\title{
The Dictyostelium model for mitochondrial biology and disease
}

\author{
XAVIER G. PEARCE, SARAH J. ANNESLEY and PAUL R. FISHER* \\ Discipline of Microbiology, La Trobe University, Victoria, Australia
}

\begin{abstract}
The unicellular slime mould Dictyostelium discoideum is a valuable eukaryotic model organism in the study of mitochondrial biology and disease. As a member of the Amoebozoa, a sister clade to the animals and fungi, Dictyostelium mitochondrial biology shares commonalities with these organisms, but also exhibits some features of plants. As such it has made significant contributions to the study of eukaryotic mitochondrial biology. This review provides an overview of the advances in mitochondrial biology made by the study of Dictyostelium and examines several examples where Dictyostelium has and will contribute to the understanding of mitochondrial disease. The study of Dictyostelium's mitochondrial biology has contributed to the understanding of mitochondrial genetics, transcription, protein import, respiration, morphology and trafficking, and the role of mitochondria in cellular differentiation. Dictyostelium is also proving to be a versatile model organism in the study both of classical mitochondrial disease e.g. Leigh syndrome, and in mitochondria-associated neurodegenerative diseases like Parkinson's disease. The study of mitochondrial diseases presents a unique challenge due to the cryptic nature of their genotypephenotype relationship. The use of Dictyostelium can contribute to resolving this problem by providing a genetically tractable, haploid eukaryotic organism with a suite of readily characterised phenotype readouts of cellular signalling pathways. Dictyostelium has provided insight into the signalling pathways involved in multiple neurodegenerative diseases and will continue to provide a significant contribution to the understanding of mitochondrial biology and disease.
\end{abstract}

KEY WORDS: Dictyostelium, mitochondrial biology, mitochondrial disease, AMPK, neurodegeneration

\section{Introduction}

Mitochondria are double-membrane-bounded organelles present in all nucleated eukaryotic cells, with few exceptions. Beyond their primary role of ATP synthesis via oxidative phosphorylation, mitochondria are also involved in many cellular processes such as calcium signalling, cellular differentiation and proliferation, and programmed cell death (Bertero and Maack, 2018, Umemoto et al., 2018, Vakifahmetoglu-Norberg et al., 2017). The mitochondrion is thought to have originated from an endosymbiotic event between a primitive eukaryote and a $\alpha$-proteobacterium (Leger et al., 2015). The strongest evidence of this is that mitochondria possess their own genome, and like bacteria, this genome is circular in structure, while the proteins it encodes are more closely related to bacterial than to eukaryotic counterparts. Indeed, eukaryotic mitochondria have retained a division system akin to that of their prokaryotic ancestors (Leger et al., 2015). Over time, many of the requisite genes for the proper functioning of mitochondria have migrated to the nuclear genome, a process that has continued more or less independently in the different phylogenetic lineages. The result is that the gene composition and size of the mitochondrial genome is different in each eukaryotic lineage, with the human mitochondrial genome being one of the most severely reduced in size (13 protein-encoding genes, $16 \mathrm{~kb}$ in size) (Wallace, 2005), while the least reduced is that of the protist Reclinomonas americana whose 69 kilobases encode 65 proteins (Burger et al., 2013).

In humans, mutations affecting either the mitochondrial genome or nuclear genes encoding mitochondrial proteins can cause complex diseases whose diverse clinical presentations break the nexus between genotype and phenotype (Stenton and Prokisch, 2018). Thus, the same genetic defect can cause very diverse clini-

Abbreviations used in this paper: ETC, electron transport chain; OXPHOS, oxidative phosphorylation; ROS, reactive oxygen species.

*Address correspondence to: Paul R. Fisher. Discipline of Microbiology, Department of Physiology Anatomy and Microbiology, La Trobe University, VIC 3086,
Australia. e-mail: P.Fisher@ @atrobe.edu.au - web: https://scholars.latrobe.edu.au/display/prfisher - (iD) https://orcid.org/0000-0003-1884-6306

Submitted: 10 June, 2019; Accepted: 22 July, 2019

ISSN: Online 1696-3547, Print 0214-6282 
cal outcomes in patients and similar disease phenotypes can be produced by multiple genetic causes (Sofou et al., 2018). Because of this complexity, the study of mitochondrial biology and disease has relied upon contributions from several model organisms, including the yeast Saccharomyces cerevisiae, and the cellular slime mould Dictyostelium discoideum.

D. discoideum belongs to the Amoebozoa, a sister clade to the Opisthokonta, the group containing fungiand animals. Dictyostelium mitochondria share many similarities with all eukaryotes, but have some features found in either animals or plants. $D$. discoideum has been used extensively as a eukaryotic model organism in the study of cellular processes such as chemotaxis, thermotaxis, motility, programmed cell death, cell differentiation, signal transduction, and human disease modelling (Maniak, 2011, Steinert and Heuner, 2005). It is also a well-established model organism for the investigation of mitochondrial genetics and in mitochondrial disease modelling (Barth et al., 2007; Francione et al., 2011). Due to its biology including several cellular processes more akin to higher eukaryotes e.g. phagocytosis, chemotaxis, and differentiation, Dictyostelium is an ideal model for the study of conserved genes not found in yeast (Torija et al., 2006). A fully sequenced nuclear and mitochondrial genome, tractability to genetic modification, and a life cycle that provides numerous phenotypic readouts of cellular processes make $D$. discoideumanattractive model for mitochondrial biology and disease. This review aims to provide an overview of $D$. discoideum mitochondrial biology and its utility as a model in understanding human mitochondrial disease mechanisms.

\section{Mitochondrial biology}

\section{Mitochondrial genetics}

The mitochondrial genome of $D$. discoideum is fully sequenced and is 55,564 bp in length with an A+ T content of 72.6\% (Ogawa et al., 2000). The genome is circular and each cell contains approximately 200 copies of the mitochondrial genome. This $A+T$ richness is a feature shared with other protozoa, fungi, nematodes, and invertebrates (Nakao et al., 2002, Stewart and Beckenbach, 2005). Despite this, unlike other organisms with similar A + T richness, $D$. discoideum appears to use the universal genetic code in its translation of mitochondrial mRNAs (Angata et al., 1995). The mitochondrial genome contains 61 genes, the majority of which, like all mitochondrial genomes, encode gene products related to respiration and translation (Ogawa et al., 2000). Interestingly, all genes are encoded on the same DNA strand, in the same orien- tation, and the genome is transcribed from a single start site (Le et al., 2009). This primary transcript is processed into eight major polycistronic transcripts which are additionally further processed into di- and tri-cistronic transcripts (Barth et al., 1999, Barth et al., 2001). D. discoideum mtDNA encodes 33 proteins, 2 ribosomal RNAs, and 18 transfer RNAgenes with many of these genes ortho-/ homologues to Homo sapiens mtDNA genes (Table 1). Notably, in humans the genes encoding ribosomal proteins have all transferred to the nuclear genome. However, the majority of common respiratory chain constituents remain encoded in the mtDNA. As expected from this "loss" of genes, the human mitochondrial genome is substantially smaller at $16,569 \mathrm{bp}$ (Anderson et al., 1981). As many of the requisite proteins for mitochondria are now encoded on the nuclear genome, many required proteins are imported into the mitochondria, including those required for transcription.

\section{Mitochondrial transcription}

Mitochondrial DNAin fungi, plants, and animals is transcribed by a nuclear-encoded mitochondrial RNA polymerase (mtRNAP) that has a high sequence similarity to bacteriophage RNA polymerases (Filée et al., 2002, Gustafsson et al., 2016, Ringel et al., 2011). Unlike bacteriophage mtRNAPs, eukaryotic mtRNAPs require additional proteins for efficient transcription, known as mitochondrial transcription factors (Falkenberg et al., 2002). Consisting of two families, mitochondrial transcription factors A\& B (mtTFA; mtTFB), together with mIRNAP, form the machinery required for mitochondrial transcription. $D$. discoideum similarly has a nuclear-encoded phage-like mitochondrial RNA polymerase, RpmA. The rpmAgene consists of a continuous open reading frame of 2,850 nucleotides in length and codes for a protein of 950 amino acid residues, within which all catalytically essential residues are conserved (Le et al., 2009). While being shown to initiate transcription, RpmA, did so inefficiently, suggesting that, like other eukaryotes $D$. discoideum requires mitochondrial transcription factors for mtDNA transcription. Manna et al., (2013) identified and characterised a $D$. discoideum mitochondrial transcription factor $B$. Identified as $t f b 1 \mathrm{~m}$, this gene is $1,458 \mathrm{bp}$ in size, with a corresponding amino acid sequence 485 residues in length, and approximately $56 \mathrm{kDa}$ in molecular weight. Tfb1m was shown to localise to the mitochondria and function both as a rRNA adenosine dimethyltransferase, but also to activate mitochondrial transcription in concert with RpmA. The dual role of methyl transferase activity and mitochondrial transcription initiation is concordant with the human homologues of $\mathrm{Tfb} 1 \mathrm{~m}$ (Cotney and Shadel, 2006). While RpmA expressed without Tfb1m

TABLE 1

\section{A COMPARISON OF DICTYOSTELIUM DISCOIDEUM AND HOMO SAPIENS MITOCHONDRIAL GENES RELATING TO RESPIRATION AND TRANSLATION}

\begin{tabular}{|c|c|c|}
\hline & Dictyostelium discoideum & Homo sapiens \\
\hline Respiratory chain & $\begin{array}{l}\text { NADH-dehydrogenase: nad1, 2, 3, 4, 4L, 5, 6, 7, 9, } 11 \\
\text { Apocytochrome b: } c o b \\
\text { Cytochrome oxidase: } \operatorname{cox} 1 / 2, \operatorname{cox} 3\end{array}$ & $\begin{array}{l}\text { NADH-dehydrogenase: MT-ND1, 2, 3, 4, 4L, 5, } 6 \\
\text { Cytochrome } b \text { : MT-CYB } \\
\text { Cytochrome } c \text { oxidase: MT-CO1, 2, } 3\end{array}$ \\
\hline Oxidative phosphorylation & $\begin{array}{l}\mathrm{F}_{0}-\text { ATPase: atp6, atp8, atp9 } \\
\mathrm{F}_{1}-\text { ATPase: atp1 }\end{array}$ & $\begin{array}{l}\mathrm{F}_{0} \text { - ATP synthase: } \\
\text { MT-ATP } 6,8\end{array}$ \\
\hline Ribosomal proteins & $\begin{array}{l}\text { Small subunit: } r p s 2, r p s 4, r p s 7, r p s 8, r p s 11, r p s 12, r p s 13, r p s 14, r p s 19 \\
\text { Large subunit: } r p / 2, r p / 5, r p / 6, r p / 11, r p / 14, r p / 16\end{array}$ & ${ }^{*} \mathrm{nDNA}$ encoded \\
\hline Ribosomal RNAs & $\begin{array}{l}\text { Large subunit: } r n l \\
\text { Small subunit } r n s\end{array}$ & $\begin{array}{l}\text { Large subunit: MT-RNR2 } \\
\text { Small subunit: MT-RNR1 }\end{array}$ \\
\hline Transfer RNAs & $\mathrm{A}, \mathrm{C}, \mathrm{E}, \mathrm{F}, \mathrm{H}, 11,12,13, \mathrm{~K}, \mathrm{~L} 1, \mathrm{~L} 2, \mathrm{M}, \mathrm{N}, \mathrm{P}, \mathrm{Q}, \mathrm{R}, \mathrm{W}, \mathrm{Y}$ & A, C, D, E, F, G, I, K, L1, L2, M, N. P, Q, R, S1, S2, T, V, W, Y \\
\hline
\end{tabular}

D. discoideum mtDNA data from (Ogawa et al., 2000). Human mitochondrial data from (Anderson et al., 1981, Capt et al., 2016). 

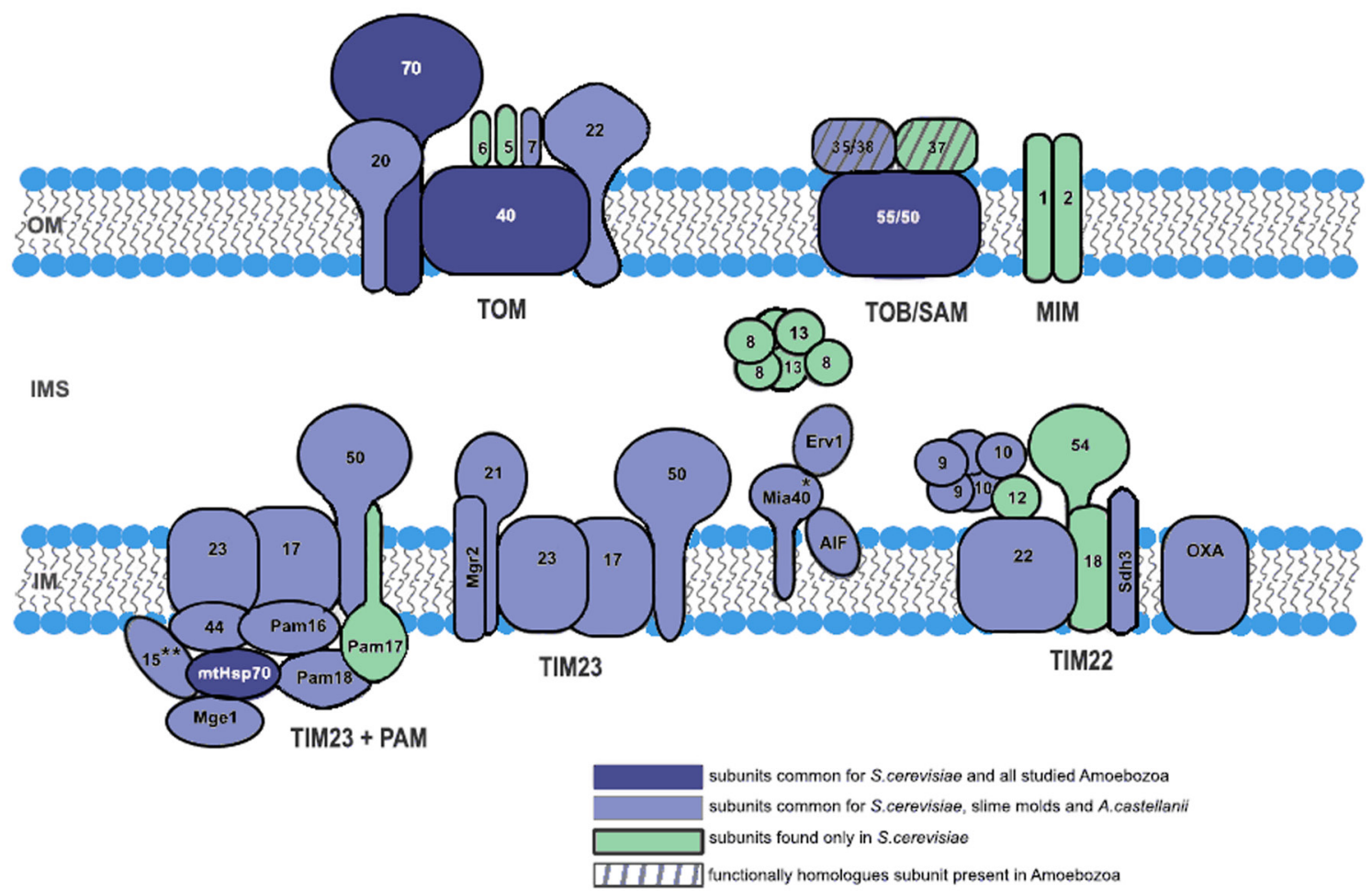

Fig. 1. The mitochondrial protein import complexes of the Amoebozoa supergroup. D. discoideum (and other Amoebozoa) share a highly similar organisation of their protein import complexes to the canonical Saccharomyces protein import complexes and other members of the Amoebozoa. Diagram reused under the terms of the Creative Commons Attribution 4.0 International License. Diagram modified from Wojtkowska et al., (2017).

produced undetectable amounts of transcripts, coexpression with Tfb1 $\mathrm{m}$ improved transcription efficiency dramatically, to the point where it was suggested that Tfb1m may be the sole transcription factor necessary for mitochondrial transcription in $D$. discoideum (Manna et al., 2013). As illustrated above, mitochondrial function is dependent on nuclear-encoded protein import and this is facilitated by the TOM/TIM complexes in mitochondria.

\section{Protein import}

As most mitochondrial proteins are encoded in the nuclear genome rather than the mitochondrial genome, mitochondria rely upon protein import and subsequent assembly for correct functioning and biogenesis. After early controversy, the demonstration that mitochondrial protein import could occur posttranslationally in vitro resulted in a long-held belief that this was the predominant mechanism, with protein synthesis occurring in the cytosol and subsequent being imported (Ahmed and Fisher, 2009, Fox, 2012). However, Dictyostelium provided an early counter demonstration that some proteins are imported into the mitochondria posttranslationally and others cotranslationally as a result of selective trafficking of the mRNA to the mitochondrial surface (Ahmed et al., 2006). It is now clear that both mechanisms are used in parallel: approximately half of the proteins that make up the mitochondrial proteome are translated at the surface of mitochondria, with the remainder being synthesized in the cytosol and posttranslationally imported (Fox, 2012). Most mitochondrial inner membrane proteins were found to be cotranslationally targeted in Saccharomyces (Williams et al., 2014). This localised translation of proteins is presumed to facilitate their correct import and assembly, however why not all mitochondrial proteins are cotranslationally imported is not fully understood (Fox, 2012). Localised synthesis of proteins coupled with their simultaneous transport is not mitochondria-specific (Aviram and Schuldiner, 2017). Similar cotranslational import of proteins also occurs in the endoplasmic reticulum, and chloroplasts (Dudek et al., 2015, Króliczewski et al., 2016). Cotranslational import of proteins now appears to be a commonplace occurrence not limited to any particular organelle, and a system used in concert with posttranslational import (Allen et al., 2019, Wiedemann and Pfanner, 2017).

Whether it occurs cotranslational or posttranslationally, the import of proteins into mitochondria is a particularly challenging problem that eukaryotes needed to "solve", due to the complex architecture of the mitochondria, requiring the bridging of two membrane delineated spaces i.e. the intermembrane space and matrix (Wojtkowska et al., 2015). The reference model of mitochondrial import machinery is that of Saccharomyces cerevisiae (Demishtein-Zohary and Azem, 2017). The complete protein import system consists of three outer membrane (TOM, TOB/SAM, MIM), four inner membrane (TIM22, TIM23, TIM23+PAM, OXA) and three mitochondrial intermembrane space assembly (MIA) complexes. Comparative sequence analysis of genome and transcriptome data by Wojtkowska et al., (2017) indicates that in D. discoideum, protein import complexes of the canonical Saccharomyces appear to be conserved with the exception of MIA (albeit with some subunit variation/loss) (Fig. 1)

TOM and TOB/SAM (topogenesis of the mitochondrial outer membrane $\beta$-barrel proteins/sorting and assembly machinery) are present and are responsible for preprotein recognition and translo- 
cation, and protein sorting and assembly, respectively (Wenz etal., 2015). TIM22 \& 23 (translocase of the inner membrane) mediate precursor protein import through the IMM, dependant on the location of the protein's import targeting signals (within sequence or $\mathrm{N}$ terminus, respectively). PAM (presequence translocase-associated motor) functions to drive translocation of proteins into the matrix. OXA (oxidase assembly factor) mediates insertion of proteins from the matrix into the inner membrane (Wenz et al., 2015).

Most protein import from the cytosol through the outer mitochondrial membrane (OMM) is facilitated by the TOM complex (Rapaport, 2002). In D. discoideum, the TOM complex consists of Tom 7, 20, 22, 40, 70 (Macasev et al., 2004, Wojtkowska et al., 2017). Tom 22 and Tom 40 are conserved in all eukaryotes with the addition of Tom7 after the divergence of the Excavates supergroup (Mani et al., 2016).

Harbauer et al., (2014) suggest that the mitochondrial import machinery should be considered a regulatory hub as impairment of protein import activity acts as a sensor for mitochondrial health and regulates biogenesis and mitochondrial cycling. Dysfunction in protein import can have deleterious effects on mitochondrial membrane potential and cause the accumulation of misfolded proteins in the intermembrane space inducing the mitochondrial stress response (Haynes et al., 2013). This triggers retrograde signalling to the nucleus and upregulation of molecular chaperones, proteases, import complex subunits and proteins in an attempt to alleviate mitochondrial stress and restore mitochondrial homeostasis (Haynes et al., 2013).

Due to its intrinsic role in cellular and mitochondrial health, and association with mitochondrial disease, a complete understanding of mitochondrial import may prove critical in the management of neurological disorders and mitochondrial diseases. Dysfunction of mitochondrial protein import mechanisms is associated with several neurological disorders. Accumulation of amyloid precursor protein in mitochondrial import channels of Alzheimer's patient brains results in the inhibition of the transport of cytochrome $c$ oxidase subunits into mitochondria, decreased cytochrome c oxidase activity and increase ROS production (Devi etal., 2006). Oligomeric $\alpha$-synuclein (the putative toxic form of the pathological agent of Parkinson's disease) binds to the TOM20 subunit of the translocase of the outer membrane (TOM), impairing protein import and causing dysfunction of respiratory Complex I (Di Maio et al., 2016).

\section{Mitochondrial morphology and trafficking}

Previously (still currently in undergraduate textbooks) depicted to be discrete bean-shaped organelles free in the cytoplasm of cells, mitochondria are now known to be more complex and dynamic in their morphology, arrangement and subcellular distribution (Tilokani et al., 2018, Wai and Langer, 2016). Mitochondria undergo continuous cycles of fusion and fission and are redistributed within the cell to areas requiring energy production (Eisner et al., 2018). Mitochondrial movement, fusion and fission are dependent on the cell cytoskeleton, both actin and microtubular, and mediated by actin and microtubule motor proteins (Woods et al., 2016).

$D$. discoideum mitochondria have been reported to be present in various proportions of spherical (66 \%), rod (24\%), and tubular $(10 \%)$ forms in fixed cells (Gilson et al., 2003). Live cell imaging via laser scanning confocal imaging, also showed they are in the main, spherical (Schimmel et al., 2012). Gilson et al., (2003) reported that $D$. discoideum has two homologues of the $\alpha$-proteobacterial bacterial fission protein, FtsZ, FszA and FszB. Homologues are also found in other eukaryotic lineages, but not in metazoa, fungi or higher plants (which do however retain plastid homologues of the cyanobacterial FtsZ). When FszA and/or FszB are knocked out, the proportions of the mitochondrial shape classes change greatly, the tubular shape being promoted, consistent with a conserved role in mitochondrial fission. Submitochondrial localisation patterns of FszA suggest that it plays a direct role in mitochondrial division with the distribution of FszA along tubular mitochondria at sites of recent or likely future divisions. The nature of FszB's role in mitochondrial division is unclear but may be indirect.

While mutation of FszA and/or FszB impaired mitochondrial fission it did not cause the complete cessation of mitochondrial division (Gilson et al., 2003). Other eukaryotes use dynamin-like proteins during mitochondrial fission and two $D$. discoideum dynamin orthologues, DymA and DymB were suggested as candidate proteins for involvement in fission. Electron micrographs of Dictyostelium dymA knockouts show the accumulation of mitochondria into dense clusters and most mitochondria taking an interconnected tubular, branching form (Wienke et al., 1999). These defects were attributed to defects in membrane trafficking processes, rather than defects in mitochondrial division directly. DymB, while being targeted to the mitochondria and playing other diverse roles in the cell, such as stabilisation of actin filaments in cytokinesis, has no obvious role in mitochondrial division (Masud Rana et al., 2013, Rai et al., 2011). Indeed, using a live cell fission and fusion assay and laser scanning confocal microscopy, Schimmel et al., (2012) demonstrated that fusion/fission rates were not affected by loss of DymA, DymB or MidA (Schimmel et al., (2012), a mitochondrial Complex I assembly factor whose loss causes a specific Complex I respiratory defect (Carilla-Latorre et al., 2010). Thus $d y m A^{-} D$. discoideum cells have aggregated spherical mitochondria, with tubular structures, but not altered fusion or fission rates, while the mitochondria in $d y m B$ - cells also approximated wildtype fission/ fusion rates. It appears that uniquely in $D$. discoideum (thus far), DymA and DymB are not essential for mitochondrial replication.

However, mitochondrial fission and fusion are affected by loss of CluA, a protein first discovered in Dictyostelium and found to be essential for normal localization of mitochondria in the cell (Zhu et al., 1997). Knocking out $D$. discoideum cluA caused clustering of the mitochondria in the perinuclear region at the centre of the cell along with some moderate growth and viability defects (Zhu et al., 1997). CluA has homologues present as open reading frames in all sequenced eukaryotic organisms (Fields et al., 2002). The mammalian homologue, CLUH, binds a specific subset of mRNAs for nuclear encoded mitochondrial proteins and its loss not only causes clustering of the mitochondria, but reduced mitochondrial biogenesis (Gao et al., 2014). Knocking out the Drosophila homologue causes morphologically abnormal mitochondria, reduced ATP levels and clustering in germ line cells that suggested unequal inheritance (Cox and Spradling, 2009, Sen et al., 2013). When the Saccharomyces cerevisiae homologue (CLU1) was expressed in clu $A^{-} D$. discoideum, the aberrant mitochondrial localisation and growth defects were remedied, indicating that CLU1 and cluA encode functional homologues (Fields et al., 1998). Despite a similar result of interconnected mitochondria as in the case of $d y m A$ - mutants, this seemed not to be due to cytoskeletal disruption, but to the late blocking of mitochondrial outer membrane fission (Fields et al., 2002). Previously hypothesised to function as a mitochondria- 
cytoskeleton linker protein, CluA has since been demonstrated not to be required for mitochondrial motility but does play an as yet unidentified role in mitochondrial fusion and fission (Woods et al., 2016). While it is known that FszA, FszB, and CluAare all essential for mitochondrial fusion and fission, it is not known whether these can account for all of the mitochondrial division activity, since there are no triple mutants available.

Pharmacological disruption of microtubules demonstrated that they are the primary cytoskeletal element involved in $D$. discoideum mitochondrial movement and distribution (Woods et al., 2016). Actin filaments appear to play a secondary role, affecting the number of mitochondria moving at one time, but not their movement speed or cellular distribution (Woods et al., 2016). The Ras-related GTPase Miro was shown in humans to play a role in the calcium-dependent regulation of mitochondrial transport along microtubules. Miro was found to play a similar role in mammals and other metazoans such as Drosophila. However in Saccharomyces, Arabidopsis, and $D$. discoideum, Miro is involved in mitochondrial morphology, inheritance and homeostasis rather than trafficking (Yamaoka and Hara-Nishimura, 2014). The $D$. discoideumorthologue of the human Miro gene is gemA. When knocked-out, gemA-mutants exhibited significant growth defects, particularly in liquid media, attributed to reduced mitochondrial mass and ATP content. Mitochondrial $\mathrm{O}_{2}$ consumption was increased in gemA-mutants, however glucose consumption and mitochondrial membrane potential remained equivalent to wildtype. Mitochondrial mass and morphology were unaffected, and mitochondrial trafficking in vivo showed no impairment (Vlahou et al., 2011). Given the commonalities in function in plants, yeasts and amoebae, Miro appears to have an ancestral function in the homeostasis of mitochondria that has been later modified in metazoans for mitochondrial transport (Yamaoka and Hara-Nishimura, 2014). An understanding of the regulation of mitochondrial dynamics is crucial, as they are essential for key cellular processes in $D$. discoideum such as differentiation and multicellular development.

\section{Mitochondrial involvement in development and differentiation}

Mitochondria have functions in regulation of the growth/differentiation transition, cell-type determination, taxis and pattern formation. $D$. discoideum cells with depleted $m$ tDNA had a delayed entry into differentiation and a cessation of development at the slug stage (Chida et al., 2004). The proportion of prestalk cells was significantly increased with concomitant reduction in prespore cells, in addition, prespore/prestalk cell patterning was disrupted (Chida et al., 2004). Similar findings of shortened fruiting body stalks indicating an increase in the proportion of prestalk cells were made in mutant strains in which expression of the essential mitochondrial protein chaperonin 60 was knocked down (Bokko et al., 2007, Kotsifas et al., 2002).

Further evidence of mitochondria's role in differentiation is that the expression of mitochondrial ribosomal protein S4 (mt-RPS4) in response to starvation is essential for the initiation of differentiation (Inazu et al., 1999, Maeda and Chida, 2013). Disruption of mrps4 within mitochondria impaired differentiation. Knockouts of mrps 4 do not aggregate after $16 \mathrm{~h}$, but do grow normally, suggesting that mt-RPS4 is not needed for growth but is essential for differentiation. Perhaps serendipitously, mt-RPS4 has several nuclear localisation signals in $D$. discoideum and was shown to localise to the nucleus in mrps4 ectopic overexpression models. Surprisingly, this overexpression of mt-RPS4 in the nucleus enhanced early differentiation, while stable nuclear expression of mrps 4 antisense RNA produced the opposite outcome. The mechanisms for these extramitochondrial actions of the mitochondrially encoded mt-RPS4 are unknown. Although not required for mitochondrial fusion/fission, the Complex I assembly factor MidA is essential for correct cellular and mitochondrial function and development (Torija et al., 2006). MidA knockout in D. discoideum leads to diverse phenotype outcomes: cell growth, size, macropinocytosis and phagocytosis were all reduced. In addition, multicellular development was arrested at the end of the slug stage. While oxygen consumption remained similar to wildtype, a significant reduction of mitochondrial ATP generation in midA-mutants was noted but without any defect in mitochondrial membrane potential or in mitochondrial number, indicating MidA involvement in ATP synthesis. Later work determined that MidA interacts with, and is required for mitochondrial Complex I function (Carilla-Latorre et al., 2010). Further discussion of MidA's role in mitochondrial respiration is discussed in the mitochondrial disease modelling section of this document.

In mitochondrially diseased $D$. discoideum, multicellular morphogenesis is disrupted, in particular fruiting body stalk and basal disk formation are abnormal, generally having shortened, thickened stalks (Kotsifas et al., 2002). Stalk-cell differentiation in $D$. discoideum is coordinated by a group of chlorinated hexaphones known as differentiation-inducing factors (DIF) (Kubohara et al., 2017, Thompson and Kay, 2000). These DIFs also are involved in chemotaxis in $D$. discoideum, a role that has created interest in these compounds for their potential as anti-metastatic cancer drugs. There are three DIF factors: DIF-1, DIF-2, and DIF-3. DIF-1 is the primary inducer of stalk cell differentiation, with DIF-2 playing a lesser role, and DIF-3 (the first metabolite resulting from the degradation of DIF-1) having effectively no activity on stalk differentiation induction (Thompson and Kay, 2000).

While their phenotypic outcomes have been well examined, the signalling pathways the DIFs act upon remain to be understood. It has been proposed that DIF-1 may function via increases in cytosolic calcium or proton concentrations (Kubohara et al., 2017). As mitochondria are integral to intracellular calcium homeostasis, they appear to be good candidate targets for DIF activity (Paupe and Prudent, 2018). A fluorescently labelled DIF-1 was shown to localise to mitochondria under early starvation or after a 21 hour incubation with cAMP (Kubohara et al., 2017). This may indicate that DIF-1 interacts with the mitochondria in its induction of stalk cell differentiation. DIFs have been shown to act as a mitochondrial uncoupler in mammalian cells (Kubohara et al., 2015). When $D$. discoideum mitochondria were uncoupled pharmacologically using CCCP (2-[2-(3-Chlorophenyl)hydrazinylyidene]propanedinitrile) or DNP (2,4-dinitrophenol), a significant but small induction of stalk cell formation was observed. This suggests that uncoupling of the mitochondria by DIF-1 only partially explains its induction of stalk cell differentiation (Kubohara et al., 2017).

DIF-1 was also shown to bind to and inhibit malate dehydrogenase (MDH) in HeLa cells (Matsuda et al., 2010). Importantly, this inhibition was isolated to the mitochondrial malate dehydrogenase $(\mathrm{mMDH})$ not the cytoplasmic isoform. MDH is an essential enzyme of the tricarboxylic acid cycle and malate-aspartate shuttle pathway. Inhibition of mMDH by DIF-1 lowered cellular ATP levels and inhibited proliferation (Matsuda et al., 2010). Interestingly, DIF-3 was able to bind to $\mathrm{mMDH}$, but did not inhibit $\mathrm{mMDH}$ enzymatic 


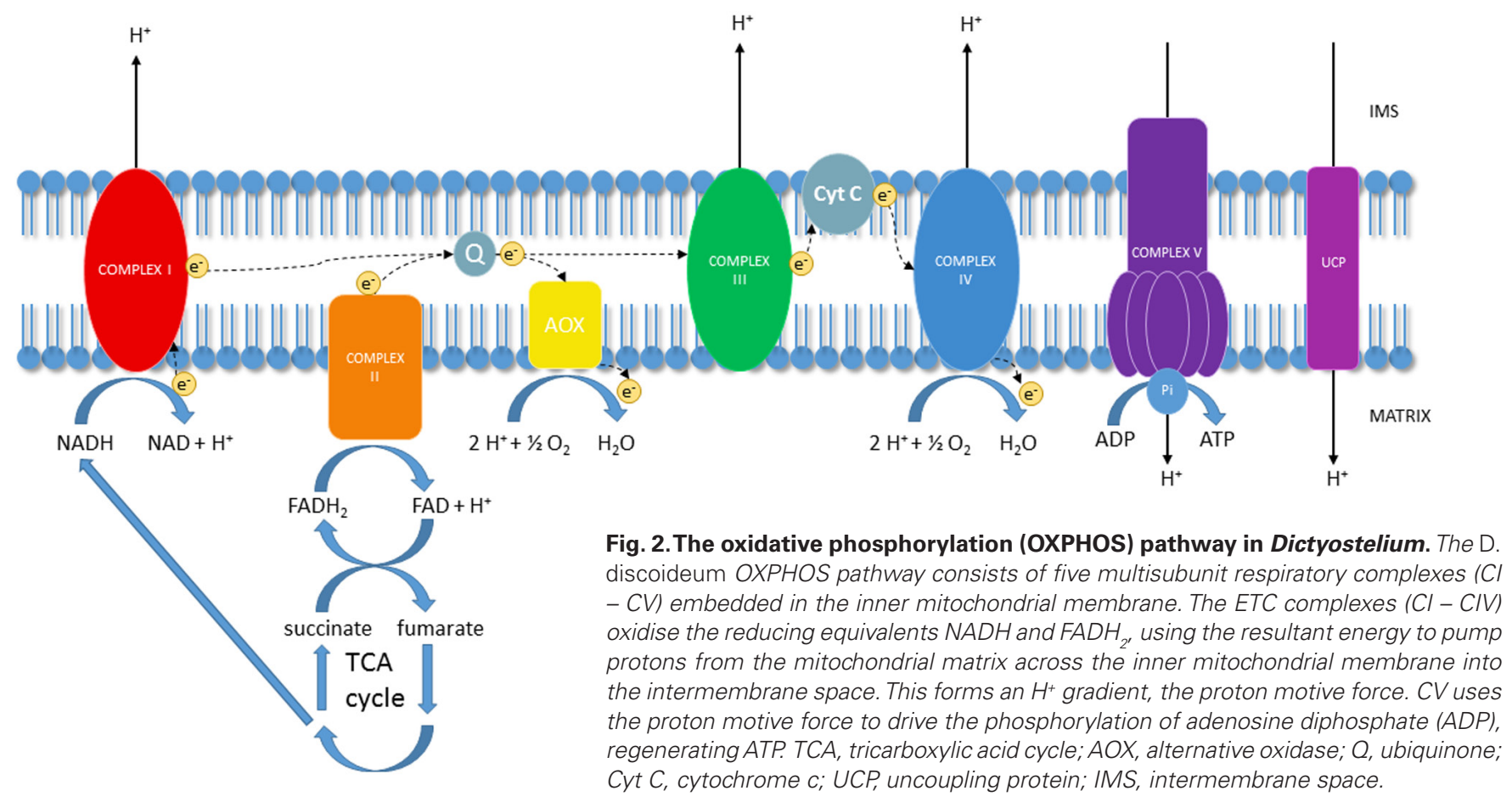

activity nor reduce cellular ATP levels, despite inhibiting HeLa cell proliferation. This parallels the observation that the DIF analogues play different roles in $D$. discoideum, i.e. DIF-3 is not a strong inducer of $D$. discoideum stalk cell differentiation whereas DIF-1 is. While it is currently unknown whether DIF-1 interacts with $D$. discoideum mitochondrial malate dehydrogenase, it appears to be a valid target for the understanding of DIF-1 induction of the stalk cell differentiation pathway and its interaction with mitochondria.

The fact that DIF-3 was able to inhibit HeLa cell proliferation without affecting ATP steady-state levels may make it a more attractive candidate as an anti-cancer compound than DIF-1 (Matsuda et al., 2010). Fluorescently labelled DIF-3 localised to the mitochondria and had deleterious effects on mitochondrial morphology and activity in HeLa cells (Kubohara et al., 2013). DIF derivative compounds also inhibited the migration of metastatic murine osteosarcoma cells in vitro (Kubohara et al., 2015). DIF-3 promotes mitochondrial fission, induces autophagy, and induces caspase-independent cell death in human leukaemia (K562 CML) lines. K562 cells treated with DIF-3 showed mitochondrial morphology transitioning from the typical network of interconnected mitochondria, to individual organelles with disrupted cristae after 3 - 6 hours, and complete absence of mitochondria after 24 hours. This had significant deleterious effects on ATP production, induced superoxide production and depleted the mitochondrial membrane potential. DIF-3 induces autophagy in K562 cells by rapid inhibition of mTOR pathway signalling as a result of dephosphorylation of mTOR at Ser2481 (Dubois et al., 2016). DIF-3 triggered caspaseindependent cell death through the induction of $\mathrm{Ca}^{2+}$ influx into the cytoplasm, and the subsequent recruitment of DRP1 to the mitochondria. K652 tumours implanted in mice were inhibited by DIF-3 treatment in food. Beneficially, the inhibition of tumour growth was not apoptotic in nature, so could bypass the apoptotic drug resistance frequently encountered in tumour cells (Dubois et al., 2016). It appears that the DIFs have significant interactions with mitochondria both in $D$. discoideum and human cancer cells and further pursuit of this relationship may provide some insight into mitochondrial roles in cellular morphogenesis.

\section{Mitochondrial respiratory function}

\section{Oxidative phosphorylation}

The primary function of the mitochondria is the production of adenosine triphosphate (ATP) by oxidative phosphorylation (OX$\mathrm{PHOS}$ ) via the electron transport chain (ETC). The OXPHOS pathway in $D$. discoideum is fundamentally the same as its mammalian counterpart, aside from the presence of an additional alternative oxidase (discussed in the following section) (Fig. 2). As the primary means of ATP production, OXPHOS function is central to cellular health and dysregulation of respiration is a common indicator of many mitochondrial diseases and disorders.

The first and largest respiratory complex in the OXPHOS pathway is NADH:ubiquinone oxidoreductase or Complex I (CI), consisting of 45 subunits in mammals with a combined weight of $970 \mathrm{kDa}$. Fourteen of these are considered "core" subunits as they comprise the minimal functional $\mathrm{Cl}$ conserved in bacteria, the remainder, so-called "accessory" subunits, in mammals have unknown roles (Fiedorczuk et al., 2016). D. discoideumpossesses proteins homologous to the core subunits, and a subset of the mammalian accessory proteins. Three subunit genes that are now encoded on the nuclear genome in mammals are encoded on the mitochondrial genome in $D$. discoideum. $\mathrm{Cl}$ couples the oxidation of NADH to the reduction of ubiquinone, and the pumping of protons. This complex is the primary contributor to respiratory electron transport and creation of the mitochondrial membrane potential. As 
a side effect of this, it is also the main site of production of reactive oxygen species which form by leakage of electrons directly to molecular $\mathrm{O}_{2}$ at the point where electrons are normally transferred via ubiquinone to Complex III. A common cause and indicator of mitochondrial disease, respiratory complex I dysfunction has been successfully modelled in $D$. discoideum, as discussed in a later section of this article.

\section{Alternative oxidase and uncoupling protein}

In addition to the classic pathway, the $D$. discoideum OXPHOS pathway has both a cyanide-resistant ubiquinol alternative oxidase (AOX), similarly to many plant and fungi mitochondria, and uncoupling proteins (UCPs) as do most eukaryotes (Jarmuszkiewicz et al., 2002, McDonald, 2008). D. discoideum AOX (AoxA) is a monomeric oxidase able to accept electrons generated via the electron transport chain, reduce oxygen to water, and generates heat from the dissipation of free-energy (McDonald, 2008). This decreases the yield of oxidative phosphorylation overall but provides a cyanide-resistant alternative pathway for mitochondrial respiration to continue if the cytochrome $c$ oxidase pathway is inhibited. UCP also reduces oxidative phosphorylation yield by dissipation of the $\mathrm{H}^{+}$gradient generated by the ETC.

AOX and UCPs are used for thermogenesis in plants and mammals, respectively. However, in unicellular eukaryotes, like $D$. discoideum, any thermal differential with the environment would be quickly dissipated. Therefore, their purpose in $D$. discoideum is likely that of an energy-dissipation system for modulation of the reduction of ETC components. AOX and UCP both decrease the formation of reactive oxygen species (ROS), so may protect mitochondria from DNA damage, and the initiation of programmed cell death by preventing the over-reduction of the ETC chain (McDonald, 2008, Popov et al., 1997). AoxA was also suggested to play a role in multicellular differentiation of $D$. discoideum, since pharmacological inhibition of AoxA in starved amoebae triggered differentiation into stalk-like sterile cells (Kimura et al., 2010). However, AoxA null strains developed normally under unstressed conditions. This apparent contradiction suggests that the phenotypes exhibited during pharmacological inhibition may not be due solely to the inhibition of AoxA (Kimura et al., 2010). It is possible that the AOX inhibitor also caused oxidative or some other stress in the treated cells, in addition to inhibiting AoxA. When stressed with hydrogen peroxide, the development of AoxA null strains was significantly impaired, in that the mutants were unable to aggregate (Kimura et al., 2010).

Since AoxA is needed in oxidatively stressed cells for the transition from growth to aggregation, it must be expressed at that time. Jarmuszkiewicz et al., (2002) used antibodies against plant AOX to assay expression of Dictyostelium AoxA. They found that the protein is expressed continuously in the lifecycle of $D$. discoideum, but its expression levels changed significantly during development. AoxA expression was significantly higher during exponential growth than during stationary phase (20-fold) (Jarmuszkiewicz et al., 2002). However, inducing aggregation of exponentially growing cells by starvation caused the maintenance of AoxA levels at $50 \%$ of exponential growth. Maintenance of AoxA levels during starvation-induced development may be necessary for the correct developmental stalk/spore ratio in the fruiting body stage (Jarmuszkiewicz et al., 2002).

A similar approach to studying $D$. discoideum UCP expression revealed it to be constant throughout growth and development, suggesting a constant need for its activity whatever the life-stage (Jarmuszkiewicz et al., 2004). While its expression level remained constant, $D$. discoideum UCP was activated by free fatty acids, and consequently dissipated the mitochondrial membrane potential. Doing so should reduce the generation of ROS and so may provide a "safety valve" for the cell, with UCP acting indirectly as an antioxidant (Jarmuszkiewicz et al., 2004).

More recent bioinformatic analysis indicates that Dictyostelium has three uncoupling protein isoforms: UcpA, UcpB, and UcpC (Satre et al., 2007). Due to their similar size (33 kDa, $31 \mathrm{kDa}$, and $35 \mathrm{kDa}$, respectively) it is unclear whether an individual isoform or the sum of all their expression was detected using the plantderived antibodies. Therefore, it is possible that individual isoforms may differ in their expression during growth and development, and further investigation of this is warranted. Overall, AOX and UCP appear to provide a means of relieving ROS generation during high metabolic activity e.g. during exponential growth, and additionally AOX has a role in multicellular development in $D$. discoideum.

\section{Mitochondrial disease modelling in Dictyostelium}

\section{Mitochondrial disease characteristics}

Diseases involving mitochondrial dysfunction can be broadly divided into two groups: diseases that arise from a direct primary mitochondrial cause, typically mutations directly affecting the activity or expression of mitochondrial proteins, and those that originate elsewhere but have effects on the mitochondria. Primary mitochondrial diseases in humans cause a range of diverse outcomes including myopathy, diabetes, kidney disease, epilepsy, autism, blindness, deafness, heart disease, and cancer (Kalyanaraman et al., 2018). Diseases of nonmitochondrial origin that involve mitochondrial dysfunction include many neurodegenerative and neurological disorders such as retinitis pigmentosa, Parkinson's disease, Alzheimer's disease, and amyotrophic lateral sclerosis (Onyango et al., 2017, Park et al., 2006, Reddy and Beal, 2005).

A primary mitochondrial disease may be caused by inherited or acquired mutations in mitochondrial or nuclear-encoded mitochondrial genes and manifest phenotypically by impacting the ATP production of mitochondria (Alston et al., 2017). As mitochondrial genomes exist in multiple copies in each mitochondrion, and each mitochondrion is one of hundreds in each cell, mutations in the mtDNA may occur in only a proportion of the mitochondrial population, a state known as heteroplasmy (Stefano and Kream, 2016). The proportions of mutant mitochondrial genomes can vary between individuals, between tissues in an individual, and change with age. Phenotypic outcomes of mitochondrial diseases are determined by how large a proportion of the mitochondrial population is affected (mutant load) (Stewart and Chinnery, 2015). The appearance of a phenotype requires a mutant load threshold to be reached. For example, mutations in ATPase 6 ( $\mathrm{m} .8993 \mathrm{~T}>\mathrm{G}$ ) will cause neuropathy, ataxia and retinitis pigmentosa (NARP) when heteroplasmy is between 60 and $90 \%$ and develop Leigh syndrome when $>90 \%$ (Claeys et al., 2016). If the same position is mutated differently, i.e. m8993T $>C$ then Leigh syndrome develops in homoplasy and a $>90 \%$ heteroplasmy will cause NARP (Weerasinghe et al., 2018). Furthermore, Leigh syndrome can also be caused by more than 75 other mutations in entirely separate genes e.g. loss of function of a subunit of Respiratory Complex II, sdhA(Lake et al., 2016). Defects 
in the same respiratory complex can also give rise to multiple disorders. Dysfunction of Respiratory Complex I can cause a number of diseases including MELAS syndrome, Parkinsonism, Leber's disease, and Leigh syndrome (Rodenburg, 2016). In addition to mutant load, cells at particular risk of mitochondrial dysfunction are those that have high energy requirements such as the cerebrum, muscles, and neurons (Zhao et al., 2019). Therefore, in some tissues where energy requirements are lower, the cells are not diseased, whereas in others with high ATP demand, the mutant load may be high enough to cause disease e.g. retinitis pigmentosa (Petit et al., 2018). The complexity and difficulty in studying mitochondrial diseases emphasises the need for a simpler model organism such as Dictyostelium discoideum to clarify these complex phenotypes and provide the basis for investigating the signalling pathways involved and the downstream cellular consequences.

\section{Dictyostelium models of mitochondrial disease}

$D$. discoideum provides a well-established model for the study of mitochondrial disease. Presented here is a discussion of some mitochondrial disease modelling from all areas of mitochondrial cellular involvement. $D$. discoideum mitochondrial disease models have been developed that fall into two categories: those with direct primary involvement of mitochondrial genes and proteins, and those where there is mitochondrial involvement, but the disease aetiology is not mitochondrial.

The first $D$. discoideum model of mitochondrial disease was created via the mutation of the mitochondrially encoded large ribosomal RNA subunit gene, rnl (Wilczynska et al., 1997). This created a heteroplasmic mitochondrial mutant strain with aberrant phototaxis. Further investigation of heteroplasmic mitochondrial mutations in $D$. discoideum revealed that a common phenotypic signature was shared across strains (Francione, 2008, Wilczynska et al., 1997). This signature phenotype includes impaired growth, both on bacterial lawns and in liquid media, deranged phototaxis and thermotaxis, defective multicellular morphogenesis with shortened and thickened fruiting body stalks, and susceptibility to Legionella proliferation within the amoeba (Francione et al., 2009). Interestingly, the antisense inhibition of the $D$. discoideum chaperonin 60 gene, a protein required for the correct folding of proteins within mitochondria, caused the same aberrant phenotypes (Bokko et al., 2007). Chaperonin 60 knockdown causes an overall knockdown in respiratory activity without specific respiratory complex deficiency (Jasim, 2018). This is not unexpected as chaperonin 60 has a generalised role in mitochondrial protein folding (Henderson et al., 2013). These phenotypes are similar to phenotypes observed when the mitochondrial genome is depleted by ethidium bromide treatment (Chida et al., 2004).

How might these phenotypes arise? Kotsifas et al., (2002) suggested that signal transduction is more readily disrupted by energy depletion than cellular activities. Signal transduction is energetically expensive and the most obvious a prioriprediction of mitochondrial genome dysfunction in mitochondrial disease is that many of the manifested phenotypes would be due to a shortfall in the production of ATP. The depletion of ATP would cause disease through disruption of cellular activities, and those activities/tissues with high energy requirements would be most affected. However, it has been shown in $D$. discoideum, that mitochondrial disease phenotypes in these cases are attributable to chronic AMP-activated protein kinase (AMPK) signalling rather the direct result of ATP insufficiency (Bokko et al., 2007, Francione et al., 2009). AMPK is an energy-sensing protein kinase responsible for maintaining ATP homeostasis by inhibiting anabolic processes, such as growth and proliferation, and promoting ATP-generating pathways, such as mitochondrial biogenesis and fatty acid oxidation. The net result is that ATP homeostasis in maintained by chronic activation of AMPK with the downstream phenotypic consequences of this activation being a permanent feature. Antisense inhibition of AMPK in the $D$. discoideum mitochondrial disease models rescued the defective phenotypes where the respiratory activity of the mitochondria was broadly affected (Bokko et al., 2007).

Bolstering the case for AMPK's role, similar phenotypic consequences were observed when specific respiratory complexes were impaired. As previously discussed, MidA plays a role in $D$. discoideum development. MidA is the $D$. discoideum orthologue of human NDUFAF7 protein, an arginine methyltransferase that is required for the assembly and function of mitochondrial complex I (Cl) (Carilla-Latorre et al., 2010, Hameed et al., 2018). D. discoideum midA knockout disrupted phototaxis and thermotaxis, growth and multicellular development. The defects in phototaxis and thermotaxis were found to be entirely and the growth defects partially mediated by chronic activation of AMPK (Carilla-Latorre et al., 2010). Analysis of respiration in $\operatorname{mid} A$ null and $\operatorname{mid} A$ catalytic site point mutants by Seahorse respirometry confirmed the critical and specific role of MidA in proper functioning of $\mathrm{Cl}$, with a significant reduction of protonophore-uncoupled, whole cell $\mathrm{O}_{2}$ consumption attributable to $\mathrm{Cl}$, unaccompanied by defects in other respiratory complexes measured (CII \& CV). The proportion of basal $\mathrm{O}_{2}$ consumed for ATP production was unchanged in the midA mutants, as expected if AMPK is chronically activated to maintain ATP homeostasis (Hameed et al., 2018).

The second category of $D$. discoideum mitochondrial dysfunction models are those that have mitochondrial involvement not directly related to respiration. While not considered classical mitochondrial diseases, there is evidence that mitochondrial dysfunction is involved in the pathogenesis of neurodegenerative diseases such as Alzheimer's disease (AD) and Parkinson's disease (PD) (Viscomi et al., 2016). Several known genetic mutations in familial Parkinson's (PD) affect human mitochondria-associated proteins such as PRKN, PINK1, DJ-1, HTRA2, and LRRK2 with corresponding mitochondrial dysfunction (Kalinderi et al., 2016, Narendra, 2016). Attractively, D. discoideum does not endogenously express some of these proteins so they can be studied in a naïve cell to determine their putative interacting partners and possible cytotoxic mechanisms. Alternatively, where native homologues of human disease related proteins exist in $D$. discoideum, they can be readily manipulated and analysed.

Discussed here are two recent $D$. discoideum models that have been created to study the involvement of mitochondrial dysfunction in neurodegenerative diseases.

Respiratory Complex I defects have been reported in postmortem PD brain samples (Larsen et al., 2018). Chronic exposure to pesticides, such as rotenone, a respiratory Complex 1 inhibitor, has been associated epidemiologically with PD (Betarbet et al., 2000). Treatment of rats with rotenone resulted in the depletion of dopaminergic neurons and induced PD-like symptoms (Alam and Schmidt, 2002). When D. discoideum cells were treated with rotenone, it disrupted the cytoskeletal trafficking of mitochondria, inhibited mitochondrial fusion, and increased ROS levels without 
affecting ATP levels (Chernivec etal., 2018). Disrupted mitochondrial dynamics and ROS damage were implied to possibly contribute to the loss of neurons in PD due to their high energy requirement and reliance on mitochondrial movement (Chernivec et al., 2018).

HTRA2 is a nuclear encoded serine protease which, when mutated, can cause late-onset Parkinson's disease (Fu et al., 2017). HTRA2 is localised to the mitochondrial intermembrane space in normal conditions and is believed to perform a positive, protective role against cellular stress and also function as a transducer of mitochondrial stress signals (Strauss etal., 2005). Exposure to cellular stresses causes the release of HTRA2 to the cytosol, where it binds to inhibitors of apoptosis, deactivating their inhibition of caspases, initiating programmed cell death (Martins et al., 2002). HTRA2 deletion causes mitochondrial dysfunction and PD-like features (Martins et al., 2004). PD patient-associated mutations in HTRA2 caused the deactivation of the protease activity of HTRA2 when replicated in neuroblastoma SH-SY5Y-derived cell lines (Strauss et al., 2005). In addition, some of these mutant cell lines were more susceptible to staurosporine-induced cellular stress (Strauss et al., 2005). Furthermore, HTRA2 interacts with PINK1, a protein kinase associated with early onset PD, and forming part of the same stress-sensing pathway. HTRA2 phosphorylation is PINK1-dependent and occurs adjacent to a site of a known PDassociated mutation (Plun-Favreau et al., 2007). However, it is not entirely understood how HTRA2 mutations cause PD, and whether this is due to a reduction or increase in its serine protease activity or related to its role in cell death.

The single $D$. discoideum homologue of human HTRA2, also called HTRA2, appears to play a conserved cytoprotective role (Chen et al., 2018). Antisense inhibition and overexpression of a catalytically inactive form of $D$. discoideum HTRA2 both resulted in defects in morphogenesis and growth but did not affect phototaxis. This suggests that HTRA2 inhibition does not affect mitochondrial ATP production and therefore does not chronically activate AMPK (Chen et al., 2018). The protective role of HTRA2 appears contingent on its expression level. Overexpressed wildtype HTRA2 was cytotoxic in $D$. discoideum, even without translocation to the cytosol, evidently due to its serine protease activity, since a protease-dead mutant form could be overexpressed. Overexpressing active HTRA2 may cause the depletion of proteins essential to mitochondrial function and thereby have triggered cell death pathways (Chen et al., 2018). An alternative hypothesis is that overexpression may have caused an accumulation of active, cytotoxic protease in the cytosol by breaching the maximum capacity for mitochondrial import of the protein. However, the protease-dead GFP-tagged HtrA did not accumulate in the cytosol when overexpressed but was correctly targeted to the mitochondria.

\section{Conclusion}

It is clear that the study of mitochondrial biology and disease in $D$. discoideum has yielded valuable insight into the inner workings of eukaryotic mitochondria and begun to tease out the complexities of human mitochondrial disease. Some of the proteins with conserved roles in mitochondrial biology, notably MidA and CluA, were first discovered and studied in Dictyostelium. In other cases, Dictyostelium has helped reveal ancient protein functions, such as the role of Miro in mitochondrial homeostasis or FszA in mitochondrial fission, that have been conserved in some eukaryotic lineages but modified or lost in metazoa.

Both classical mitochondrial disease and mitochondria-associated neurodegenerative disease models have been successfully created in $D$. discoideum. Mitochondrial disease modelling in $D$. discoideum first revealed that the deficiency in ATP production may not directly cause disease phenotypes by inhibition of cellular activities, rather, that they may be caused by the chronic activation of AMPK in an attempt to restore energy homeostasis. As no effective therapies currently exist for mitochondrial disorders, this knowledge may be critical in the treatment or alleviation of mitochondrial disease symptoms. By bridging the gap between yeast models and higher eukaryotes, $D$. discoideum is well placed to continue contributing further in our understanding of mitochondrial biology, and by extension, eukaryotic cell biology.

\section{Acknowledgements}

XGP received an Australian Postgraduate Research Award. This work was supported by the Australian Research Council Discovery Project grant to PRF and SJA (DP140104276). We are grateful to Claire Storey for her invaluable assistance drafting the manuscript.

\section{References}

AHMED, A.U., GILSON, P.R., LAY, S.T., BEECH, P.L. and FISHER, P.R. (2006) Import-associated translational inhibition - novel in vivo evidence for cotranslational protein import into Dictyostelium mitochondria. Eukaryotic Cell 5: 1314-1327.

AHMED, A.U. and FISHER, P.R. (2009). Chapter 2 Import Of Nuclear-Encoded Mitochondrial Proteins: A Cotranslational Perspective. In International Review of Cell and Molecular Biology, vol. 273. Academic Press, pp.49-68.

ALAM, M. and SCHMIDT, W.J. (2002). Rotenone destroys dopaminergic neurons and induces parkinsonian symptoms in rats. Behav. Brain Res. 136: 317-324.

ALLEN, W.J., COLLINSON, I. and RÖMISCH, K. (2019). Post-Translational Protein Transport by the Sec Complex. Trends Biochem. Sci.

ALSTON, C.L., ROCHA, M.C., LAX, N.Z., TURNBULL, D.M. and TAYLOR, R.W. (2017) The genetics and pathology of mitochondrial disease. J. Pathol. 241: 236-250.

ANDERSON, S., BANKIER, A.T., BARRELL, B.G., DEBRUIJN, M.H., COULSON, A.R. DROUIN, J., EPERON, I.C., NIERLICH, D.P., ROE, B.A. and SANGER, F. (1981). Sequence and organization of the human mitochondrial genome. Nature290: 457.

ANGATA, K., KUROE, K., YANAGISAWA, K. and TANAKA, Y. (1995). Codon usage, genetic code and phylogeny of Dictyostelium discoideum mitochondrial DNA as deduced from a 7.3-kb region. Curr. Genet. 27: 249-256.

AVIRAM, N. and SCHULDINER, M. (2017). Targeting and translocation of proteins to the endoplasmic reticulum at a glance. J Cell Sci 130: 4079-4085.

BARTH, C., GREFERATH, U., KOTSIFAS, M. and FISHER, P.R. (1999). Polycistronic transcription and editing of the mitochondrial small subunit (SSU) ribosomal RNA in Dictyostelium discoideum. Curr Genet 36: 55-61.

BARTH, C., GREFERATH, U., KOTSIFAS, M., TANAKA, Y., ALEXANDER, S., ALEXANDER, H. and FISHER, P. (2001). Transcript mapping and processing of mitochondrial RNA in Dictyostelium discoideum. Curr Genet. 39: 355-564.

BERTERO, E. and MAACK, C. (2018). Calcium signaling and reactive oxygen species in mitochondria. Circulation Res. 122: 1460-1478.

BETARBET, R., SHERER, T.B., MACKENZIE, G., GARCIA-OSUNA, M., PANOV, A.V. and GREENAMYRE, J.T. (2000). Chronic systemic pesticide exposure reproduces features of Parkinson's disease. Nat Neurosci 3: 1301-6.

BOKKO, P.B., FRANCIONE, L., BANDALA-SANCHEZ, E., AHMED, A.U., ANNES LEY, S.J., HUANG, X., KHURANA, T., KIMMEL, A.R. and FISHER, P.R. (2007). Diverse cytopathologies in mitochondrial disease are caused by AMP-activated protein kinase signaling. Mol Biol Cell 18: 1874-86.

BURGER, G., GRAY, M.W., FORGET, L. and LANG, B.F. (2013). Strikingly bacterialike and gene-rich mitochondrial genomes throughout jakobid protists. Genome Biol. Evol. 5: 418-438

CAPT, C., PASSAMONTI, M. and BRETON, S. (2016). The human mitochondrial genome may code for more than 13 proteins. Mitochondrial DNAPartA27:3098-3101. 
CARILLA-LATORRE, S., GALLARDO, M.E., ANNESLEY, S.J., CALVO-GARRIDO, J., GRANA, O., ACCARI, S.L., SMITH, P.K., VALENCIA, A., GARESSE, R., FISHER, P.R. et al., (2010). MidA is a putative methyltransferase that is required for mitochondrial complex I function. J Cell Sci 123: 1674-83.

CHEN, S., SANISLAV, O., ANNESLEY, S.J. and FISHER, P.R. (2018). Mitochondrial HTRA2 Plays a Positive, Protective Role in Dictyostelium discoideum but Is Cytotoxic When Overexpressed. Genes (Basel) 9.

CHERNIVEC, E., COOPER, J. and NAYLOR, K. (2018). Exploring the Effect of Rotenone-A Known Inducer of Parkinson's Disease-On Mitochondrial Dynamics in Dictyostelium discoideum. Cells 7.

CHIDA, J., YAMAGUCHI, H., AMAGAI, A. and MAEDA, Y. (2004). The necessity of mitochondrial genome DNA for normal development of Dictyostelium cells. $J$ Cell Sci 117: 3141-52.

CLAEYS, K.G., ABICHT, A., HÄUSLER, M., KLEINLE, S., WIESMANN, M., SCHULZ, J.B., HORVATH, R. and WEIS, J. (2016). Novel genetic and neuropathological insights in neurogenic muscle weakness, ataxia, and retinitis pigmentosa (NARP). Muscle Nerve 54: 328-333.

COTNEY, J. and SHADEL, G. (2006). Evidence for an Early Gene Duplication Event in the Evolution of the Mitochondrial Transcription Factor B Family and Maintenance of rRNA Methyltransferase Activity in Human mtTFB1 and mtTFB2. J. Molec. Evol. 63: 707-717.

COX, R.T. and SPRADLING, A.C. (2009). Clueless, a conserved Drosophila gene required for mitochondrial subcellular localization, interacts genetically with parkin. Dis Model Mech 2: 490-499.

DEMISHTEIN-ZOHARY, K. and AZEM, A. (2017). The TIM23 mitochondrial protein import complex: function and dysfunction. Cell Tissue Res. 367: 33-41.

DEVI, L., PRABHU, B.M., GALATI, D.F., AVADHANI, N.G. and ANANDATHEERTHAVARADA, H.K. (2006). Accumulation of amyloid precursor protein in the mitochondrial import channels of human Alzheimer's disease brain is associated with mitochondrial dysfunction. J. Neuroscience 26: 9057-9068.

DI MAIO, R., BARRETT, P.J., HOFFMAN, E.K., BARRETT, C.W., ZHARIKOV, A., BORAH, A., HU, X., MCCOY, J., CHU, C.T. and BURTON, E.A. (2016). $\alpha$-Synuclein binds to TOM20 and inhibits mitochondrial protein import in Parkinson's disease. Sci. Trans. Med. 8: 342ra78-342ra78.

DUBOIS, A., GINET, C., FURSTOSS, N., BELAID, A., HAMOUDA, M.A., EL MANAA, W., CLUZEAU, T., MARCHETTI, S., RICCI, J.E., JACQUEL, A. et al., (2016). Differentiation inducing factor 3 mediates its anti-leukemic effect through ROS-dependent DRP1-mediated mitochondrial fission and induction of caspaseindependent cell death. Oncotarget 7: 26120-26136.

DUDEK, J., PFEFFER, S., LEE, P.-H., JUNG, M., CAVALIÉ, A., HELMS, V., FÖRSTER, F. and ZIMMERMANN, R. (2015). Protein transport into the human endoplasmic reticulum. J. Molec. Biol. 427: 1159-1175.

EISNER, V., PICARD, M. and HAJNÓCZKY, G. (2018). Mitochondrial dynamics in adaptive and maladaptive cellular stress responses. Nat. Cell Biol 20: 755.

FALKENBERG, M., GASPARI, M., RANTANEN, A., TRIFUNOVIC, A., LARSSON, N.-G. and GUSTAFSSON, C.M. (2002). Mitochondrial transcription factors B1 and B2 activate transcription of human mtDNA. Nat. Genet. 31: 289

FIEDORCZUK, K., LETTS, J.A., DEGLIESPOSTI, G., KASZUBA, K., SKEHEL, M. and SAZANOV, L.A. (2016). Atomic structure of the entire mammalian mitochondrial complex I. Nature 538: 406.

FIELDS, S.D., ARANA, Q., HEUSER, J. and CLARKE, M. (2002). Mitochondrial membrane dynamics are altered in cluA- mutants of Dictyostelium. $J$ Muscle Res Cell Motil 23: 829-838.

FIELDS, S.D., CONRAD, M.N. and CLARKE, M. (1998). The S. cerevisiae CLU1 and D. discoideum cluA genes are functional homologues that influence mitochondrial morphology and distribution. J Cell Sci 111: 1717-1727.

FILÉE, J., FORTERRE, P., SEN-LIN, T. and LAURENT, J. (2002). Evolution of DNA polymerase families: evidences for multiple gene exchange between cellular and viral proteins. J. Molec. Evo. 54: 763-773.

FOX, T.D. (2012). Mitochondrial protein synthesis, import, and assembly. Genetics 192: $1203-1234$.

FRANCIONE, L., SMITH, P.K., ACCARI, S.L., TAYLOR, P.E., BOKKO, P.B., BOZZARO, S., BEECH, P.L. and FISHER, P.R. (2009). Legionella pneumophila multiplication is enhanced by chronic AMPK signalling in mitochondrially diseased Dictyostelium cells. Dis Model Mech 2: 479-489.

FRANCIONE, L.M. (2008). Mitochondrial disease in dictyostelium discoideum, (ed.
LA TROBE, U.): Thesis (Ph.D.) -- La Trobe University, 2008.

FU, K., WANG, Y., GUO, D., WANG, G. and REN, H. (2017). Familial Parkinson's Disease-Associated L166P Mutant DJ-1 is Cleaved by Mitochondrial Serine Protease Omi/HtrA2. Neurosci. Bull. 33: 685-694.

GAO, J., SCHATTON, D., MARTINELLI, P., HANSEN, H., PLA-MARTIN, D., BARTH, E., BECKER, C., ALTMUELLER, J., FROMMOLT, P. and SARDIELLO, M. (2014). CLUH regulates mitochondrial biogenesis by binding mRNAs of nuclear-encoded mitochondrial proteins. J Cell Biol 207: 213-223.

GILSON, P.R., YU, X.C., HERELD, D., BARTH, C., SAVAGE, A., KIEFEL, B.R., LAY, S., FISHER, P.R., MARGOLIN, W. and BEECH, P.L. (2003). Two Dictyostelium orthologs of the prokaryotic cell division protein FtsZ localize to mitochondria and are required for the maintenance of normal mitochondrial morphology. Eukaryot Cell 2: 1315-1326.

GUSTAFSSON, C.M., FALKENBERG, M. and LARSSON, N.-G. (2016). Maintenance and expression of mammalian mitochondrial DNA. Ann. Rev. Biochem. 85: 133-160.

HAMEED, U.F.S., SANISLAV, O., LAY, S.T., ANNESLEY, S.J., JOBICHEN, C. FISHER, P.R., SWAMINATHAN, K. and AROLD, S.T. (2018). Proteobacterial Origin of Protein Arginine Methylation and Regulation of Complex I Assembly by MidA. Cell Rep. 24: 1996-2004.

HARBAUER, A.B., ZAHEDI, R.P., SICKMANN, A., PFANNER, N. and MEISINGER, C. (2014). The protein import machinery of mitochondria-a regulatory hub in metabolism, stress, and disease. Cell Metab. 19: 357-372.

HAYNES, C.M., FIORESE, C.J. and LIN, Y.-F. (2013). Evaluating and responding to mitochondrial dysfunction: the mitochondrial unfolded-protein response and beyond. Trends Cell Biol. 23: 311-318.

HENDERSON, B., FARES, M.A. and LUND, P.A. (2013). Chaperonin 60: a paradoxical, evolutionarily conserved protein family with multiple moonlighting functions. Biological Rev. 88: 955-987.

INAZU, Y., CHAE, S. and MAEDA, Y. (1999). Transient expression of a mitochondria gene cluster including rps4 is essential for the phase-shift of Dictyostelium cells from growth to differentiation. Dev. Genet. 25: 339-352.

JARMUSZKIEWICZ, W., BEHRENDT, M., NAVET, R. and SLUSE, F.E. (2002). Uncoupling protein and alternative oxidase of Dictyostelium discoideum: occurrence, properties and protein expression during vegetative life and starvation-induced early development. FEBS Lett 532: 459-464.

JARMUSZKIEWICZ, W., CZARNA, M., SWIDA, A. and BEHRENDT, M. (2004) Uncoupling Proteins in Amoeboid Eukaryotes, Acanthamoeba castellanii, and Dictyostelium discoideum. Toxicol Mech Methods 14: 3-6.

JASIM, R.A.F. (2018). The Role of Calcium Signalling in Neurodegenerative and Mitochondrial Disease using Dictyostelium discoideum as a Simple Model. In Department of Physiology, Anatomy, and Microbiology, vol. Doctor of Philosophy (ed. Victoria, Australia: La Trobe University.

KALINDERI, K., BOSTANTJOPOULOU, S. and FIDANI, L. (2016). The genetic background of Parkinson's disease: current progress and future prospects. Acta Neurol. Scand. 134: 314-326.

KALYANARAMAN, B., CHENG, G., HARDY, M., OUARI, O., LOPEZ, M., JOSEPH J., ZIELONKA, J. and DWINELL, M.B. (2018). A review of the basics of mitochondrial bioenergetics, metabolism, and related signaling pathways in cancer cells: Therapeutic targeting of tumor mitochondria with lipophilic cationic compounds. Redox Biol. 14: 316-327.

KIMURA, K., KUWAYAMA, H., AMAGAI, A. and MAEDA, Y. (2010). Developmental significance of cyanide-resistant respiration under stressed conditions: Experiments in Dictyostelium cells. Dev. Growth Diff. 52: 645-656.

KOTSIFAS, M., BARTH, C., DE LOZANNE, A., LAY, S.T. and FISHER, P.R. (2002). Chaperonin 60 and mitochondrial disease in Dictyostelium. J Muscle Res Cell Motil 23: 839-852.

KRÓLICZEWSKI, J., PISKOZUB, M., BARTOSZEWSKI, R. and KRÓLICZEWSKA, B. (2016). ALB3 insertase mediates cytochrome b 6 Co-translational import into the Thylakoid membrane. Sci. Rep. 6: 34557

KUBOHARA, Y., KIKUCHI, H., MATSUO, Y., OSHIMA, Y. and HOMMA, Y. (2013). Mitochondria are the target organelle of differentiation-inducing factor-3, an anti-tumor agent isolated from Dictyostelium discoideum [corrected]. PLoS One 8: e72118.

KUBOHARA, Y., KIKUCHI, H., NGUYEN, V.H., KUWAYAMA, H. and OSHIMA, Y. (2017). Evidence that differentiation-inducing factor-1 controls chemotaxis and cell differentiation, at least in part, via mitochondria in D. discoideum. Biol Open 6: 741-751. 
KUBOHARA, Y., KOMACHI, M., HOMMA, Y., KIKUCHI, H. and OSHIMA, Y. (2015). Derivatives of Dictyostelium differentiation-inducing factors inhibit lysophosphatidic acid-stimulated migration of murine osteosarcoma LM8 cells. Biochem Biophys Res Commun 463: 800-805.

LAKE, N.J., COMPTON, A.G., RAHMAN, S. and THORBURN, D.R. (2016). Leigh syndrome: one disorder, more than 75 monogenic causes. Ann. Neurol. 79: 190-203.

LARSEN, S., HANSS, Z. and KRÜGER, R. (2018). The genetic architecture of mitochondrial dysfunction in Parkinson's disease. Cell Tissue Res. 373: 21-37.

LE, P., FISHER, P.R. and BARTH, C. (2009). Transcription of the Dictyostelium discoideum mitochondrial genome occurs from a single initiation site. RNA 15: 2321-2330.

LEGER, M.M., PETRU, M., ZARSKY, V., EME, L., VLCEK, C., HARDING, T., LANG, B.F., ELIAS, M., DOLEZAL, P. and ROGER, A.J. (2015). An ancestral bacterial division system is widespread in eukaryotic mitochondria. Proc Natl Acad Sci USA 112: 10239-10246.

MACASEV, D., WHELAN, J., NEWBIGIN, E., SILVA-FILHO, M.C., MULHERN, T.D. and LITHGOW, T. (2004). Tom22', an 8-kDa trans-site receptor in plants and protozoans, is a conserved feature of the TOM complex that appeared early in the evolution of eukaryotes. Mol Biol Evol 21: 1557-1564.

MAEDA, Y. and CHIDA, J. (2013). Control of cell differentiation by mitochondria, typically evidenced in dictyostelium development. Biomolec. 3: 943-966.

MANI, J., MEISINGER, C. and SCHNEIDER, A. (2016). Peeping at TOMs-Diverse Entry Gates to Mitochondria Provide Insights into the Evolution of Eukaryotes. Mol Biol Evol 33: 337-351.

MANIAK, M. (2011). Dictyostelium as a model for human lysosomal and trafficking diseases. Sem. Cell Dev. Biol. 22: 114-119.

MANNA, S., LE, P. and BARTH, C. (2013). A unique mitochondrial transcription factor B protein in Dictyostelium discoideum. PLoS One 8: e70614.

MARTINS, L.M., IACCARINO, I., TENEV, T., GSCHMEISSNER, S., TOTTY, N.F., LEMOINE, N.R., SAVOPOULOS, J., GRAY, C.W., CREASY, C.L. and DINGWALL, C. (2002). The serine protease Omi/HtrA2 regulates apoptosis by binding XIAP through a reaper-like motif. J. Biol. Chem. 277: 439-444.

MARTINS, L.M., MORRISON, A., KLUPSCH, K., FEDELE, V., MOISOI, N., TEISMANN, P., ABUIN, A., GRAU, E., GEPPERT, M. and LIVI, G.P. (2004). Neuroprotective role of the Reaper-related serine protease HtrA2/Omi revealed by targeted deletion in mice. Molec. Cell Biol. 24: 9848-9862.

MASUD RANA, A.M., TSUJIOKA, M., MIYAGISHIMA, S., UEDA, M. and YUMURA, S. (2013). Dynamin contributes to cytokinesis by stabilizing actin filaments in the contractile ring. Genes Cells 18: 621-635.

MATSUDA, T., TAKAHASHI-YANAGA, F., YOSHIHARA, T., MAENAKA, K., WATANABE, Y., MIWA, Y., MORIMOTO, S., KUBOHARA, Y., HIRATA, M. and SASAGURI, T. (2010). Dictyostelium differentiation-inducing factor-1 binds to mitochondrial malate dehydrogenase and inhibits its activity. J Pharmacol Sci 112: 320-326.

MCDONALD, A.E. (2008). Alternative oxidase: an inter-kingdom perspective on the function and regulation of this broadly distributed 'cyanide-resistant'terminal oxidase. Funct. Plant Biol. 35: 535-552.

NAKAO, M., YOKOYAMA, N., SAKO, Y., FUKUNAGA, M. and ITO, A. (2002). The complete mitochondrial DNA sequence of the cestode Echinococcusmultilocularis (Cyclophyllidea: Taeniidae). Mitochondrion 1: 497-509.

NARENDRA, D.P. (2016). Parkin/pink1 pathway for the selective isolation and degradation of impaired mitochondria. In Mitochondrial Mechanisms of Degeneration and Repair in Parkinson's Disease. Springer, pp.159-182.

OGAWA, S., YOSHINO, R., ANGATA, K., IWAMOTO, M., PI, M., KUROE, K., MATSUO, K., MORIO, T., URUSHIHARA, H., YANAGISAWA, K. et al., (2000). The mitochondrial DNA of Dictyostelium discoideum: complete sequence, gene content and genome organization. Mol Gen Genet 263: 514-519.

ONYANGO, I.G., KHAN, S.M. and BENNETT JR, J.P. (2017). Mitochondria in the pathophysiology of Alzheimer's and Parkinson's diseases. Front Biosci (Landmark Ed) 22: 854-872.

PARK, B.S., HENSON, E., QUINN, J., MANCZAK, M., REDDY, P.H. and ANEKONDA, T.S. (2006). Mitochondria are a direct site of $A \beta$ accumulation in Alzheimer's disease neurons: implications for free radical generation and oxidative damage in disease progression. Human Molec. Genet. 15: 1437-1449.

PAUPE, V. and PRUDENT, J. (2018). New insights into the role of mitochondrial calcium homeostasis in cell migration. Biochem. Biophys. Res. Comm. 500:75-86.
PETIT, L., MA, S., CIPI, J., CHENG, S.-Y., ZIEGER, M., HAY, N. and PUNZO, C (2018). Aerobic glycolysis is essential for normal rod function and controls secondary cone death in retinitis pigmentosa. Cell Rep. 23: 2629-2642.

PLUN-FAVREAU, H., KLUPSCH, K., MOISOI, N., GANDHI, S., KJAER, S., FRITH, D., HARVEY, K., DEAS, E., HARVEY, R.J., MCDONALD, N. et al., (2007). The mitochondrial protease HtrA2 is regulated by Parkinson's disease-associated kinase PINK1. Nat. Cell Biol. 9: 1243.

POPOV, V., SIMONIAN, R., SKULACHEV, V. and STARKOV, A. (1997). Inhibition of the alternative oxidase stimulates $\mathrm{H} 2 \mathrm{O} 2$ production in plant mitochondria. FEBS Lett. 415: 87-90.

RAI, A., NOTHE, H., TZVETKOV, N., KORENBAUM, E. and MANSTEIN, D.J. (2011) Dictyostelium dynamin B modulates cytoskeletal structures and membranous organelles. Cell Mol Life Sci 68: 2751-67.

RAPAPORT, D. (2002). Biogenesis of the mitochondrial TOM complex. Trends Biochem. Sci. 27: 191-197

REDDY, P.H. and BEAL, M.F. (2005). Are mitochondria critical in the pathogenesis of Alzheimer's disease? Brain Res. Rev. 49: 618-632.

RINGEL, R., SOLOGUB, M., MOROZOV, Y.I., LITONIN, D., CRAMER, P. and TEMIAKOV, D. (2011). Structure of human mitochondrial RNA polymerase. Nature 478: 269.

RODENBURG, R.J. (2016). Mitochondrial complex I-linked disease. Biochim. Biophys Acta (BBA)-Bioenergetics 1857: 938-945.

SATRE, M., MATTEI, S., AUBRY, L., GAUdET, P., PELOSI, L., BRANDOLIN, G. and KLEIN, G. (2007). Mitochondrial carrier family: Repertoire and peculiarities of the cellular slime mould Dictyostelium discoideum. Biochimie 89: 1058-1069.

SCHIMMEL, B.G., BERBUSSE, G.W. and NAYLOR, K. (2012). Mitochondrial fission and fusion in Dictyostelium discoideum: a search for proteins involved in membrane dynamics. BMC Res Notes 5: 505.

SEN, A., DAMM, V.T. and COX, R.T. (2013). Drosophila clueless is highly expressed in larval neuroblasts, affects mitochondrial localization and suppresses mitochondrial oxidative damage. PLOS One 8: e54283.

SOFOU, K., DE COO, I.F.M., OSTERGAARD, E., ISOHANNI, P., NAESS, K., DE MEIRLEIR, L., TZOULIS, C., UUSIMAA, J., LÖNNQVIST, T., BINDOFF, L.A. et al., (2018). Phenotype-genotype correlations in Leigh syndrome: new insights from a multicentre study of 96 patients. J. Med. Genet. 55: 21-27.

STEFANO, G.B. and KREAM, R.M. (2016). Mitochondrial DNA heteroplasmy in human health and disease. Biomed. Rep. 4: 259-262.

STEINERT, M. and HEUNER, K. (2005). Dictyostelium as host model for pathogenesis. Cell. Microbiol. 7: 307-314

STENTON, S.L. and PROKISCH, H. (2018). Advancing genomic approaches to the molecular diagnosis of mitochondrial disease. Essays Biochem. 62: 399-408.

STEWART, J.B. and BECKENBACH, A.T. (2005). Insect mitochondrial genomics: the complete mitochondrial genome sequence of the meadow spittlebug Philaenus spumarius (Hemiptera: Auchenorrhyncha: Cercopoidae). Genome 48: 46-54.

STEWART, J.B. and CHINNERY, P.F. (2015). The dynamics of mitochondrial DNA heteroplasmy: implications for human health and disease. Nat. Rev. Genet. 16:530.

STRAUSS, K.M., MARTINS, L.M., PLUN-FAVREAU, H., MARX, F.P., KAUTZMANN S., BERG, D., GASSER, T., WSZOLEK, Z., MÜLLER, T., BORNEMANN, A. et al., (2005). Loss of function mutations in the gene encoding Omi/HtrA2 in Parkinson's disease. Human Mol. Genet. 14: 2099-2111.

THOMPSON, C.R. and KAY, R.R. (2000). The role of DIF-1 signaling in Dictyostelium development. Mol. Cell 6: 1509-1514.

TILOKANI, L., NAGASHIMA, S., PAUPE, V. and PRUDENT, J. (2018). Mitochondria dynamics: overview of molecular mechanisms. Essays Biochem. 62: 341-360.

TORIJA, P., VICENTE, J.J., RODRIGUES, T.B., ROBLES, A., CERDAN, S., SASTRE, L., CALVO, R.M. and ESCALANTE, R. (2006). Functional genomics in Dictyostelium: MidA, a new conserved protein, is required for mitochondrial function and development. J Cell Sci 119: 1154-1164.

UMEMOTO, T., HASHIMOTO, M., MATSUMURA, T., NAKAMURA-ISHIZU, A. and SUDA, T. (2018). Ca $<$ sup $>2+</$ sup $>$-mitochondria axis drives cell division in hematopoietic stem cells. J. Exp. Med. 215: 2097-2113.

VAKIFAHMETOGLU-NORBERG, H., OUCHIDA, A.T. and NORBERG, E. (2017) The role of mitochondria in metabolism and cell death. Biochem. Biophys. Res. Comm. 482: 426-431.

VISCOMI, C., ARDISSONE, A. and ZEVIANI, M. (2016). Mitochondrial Genes and 


\section{X.G. Pearce et al.}

Neurodegenerative Disease. In Mitochondrial Dysfunction in Neurodegenerative Disorders. Springer, pp.81-106.

VLAHOU, G., ELIAS, M., VON KLEIST-RETZOW, J.C., WIESNER, R.J. and RIVERO, F. (2011). The Ras related GTPase Miro is not required for mitochondrial transport in Dictyostelium discoideum. Eur J Cell Biol 90: 342-355.

WAI, T. and LANGER, T. (2016). Mitochondrial dynamics and metabolic regulation. Trends Endocrinol. Metab. 27: 105-117.

WALLACE, D.C. (2005). A mitochondrial paradigm of metabolic and degenerative diseases, aging, and cancer: a dawn for evolutionary medicine. Annu. Rev. Genet. 39: 359-407.

WEERASINGHE, C.A.L., BUI, B.H.T., VU, T.T., NGUYEN, H.L.T., PHUNG, B.K. NGUYEN, V.M., PHAM, V.A., CAO, V.H. and PHAN, T.N. (2018). Leigh syndrome T8993C mitochondrial DNA mutation: Heteroplasmy and the first clinical presentation in a Vietnamese family. Molec. Med. Rep. 17: 6919-6925.

WENZ, L.-S., OPALIŃSKI, Ł., WIEDEMANN, N. and BECKER, T. (2015). Cooperation of protein machineries in mitochondrial protein sorting. BBA - Molec. Cell Res.1853: 1119-1129.

WIEDEMANN, N. and PFANNER, N. (2017). Mitochondrial machineries for protein import and assembly. Annu. Rev. Biochem. 86: 685-714.

WIENKE, D.C., KNETSCH, M.L.W., NEUHAUS, E.M., REEDY, M.C. and MANSTEIN, D.J. (1999). Disruption of a Dynamin Homologue Affects Endocytosis, Organelle Morphology, and Cytokinesis in Dictyostelium discoideum. Molec. Biol. Cell 10: 225-243.

WILCZYNSKA, Z., BARTH, C. and FISHER, P.R. (1997). Mitochondrial mutations impair signal transduction in Dictyostelium discoideum slugs. Biochem Biophys Res Commun 234: 39-43.

WILLIAMS, C.C., JAN, C.H. and WEISSMAN, J.S. (2014). Targeting and plasticity of mitochondrial proteins revealed by proximity-specific ribosome profiling. Science 346: 748-751.

WOJTKOWSKA, M., BUCZEK, D., STOBIENIA, O., KARACHITOS, A., ANTONIEWICZ, M., SLOCINSKA, M., MAKALOWSKI, W. and KMITA, H. (2015). The TOM Complex of Amoebozoans: the Cases of the Amoeba Acanthamoeba castellani and the Slime Mold Dictyostelium discoideum. Protist 166: 349-362.

WOJTKOWSKA, M., BUCZEK, D., SUZUKI, Y., SHABARDINA, V., MAKALOWSKI, W and KMITA, H. (2017). The emerging picture of the mitochondrial protein import complexes of Amoebozoa supergroup. BMC Genomics 18: 997.

WOODS, L.C., BERBUSSE, G.W. and NAYLOR, K. (2016). Microtubules Are Essential for Mitochondrial Dynamics-Fission, Fusion, and Motility-in Dictyostelium discoideum. Front Cell Dev Biol 4: 19.

YAMAOKA, S. and HARA-NISHIMURA, I. (2014). The mitochondrial Ras-related GTPase Miro: views from inside and outside the metazoan kingdom. Front Plant Sci 5: 350 .

ZHAO, X.Y., LU, M.H., YUAN, D.J., XU, D.E., YAO, P.P., JI, W.L., CHEN, H., LIU, W.L., YAN, C.X., XIA, Y.Y. et al., (2019). Mitochondrial Dysfunction in Neural Injury. Front Neurosci 13: 30.

ZHU, Q., HULEN, D., LIU, T. and CLARKE, M. (1997). The cluA- mutant of Dictyostelium identifies a novel class of proteins required for dispersion of mitochondria. Proc Natl Acad Sci USA 94: 7308-7313. 


\section{Further Related Reading, published previously in the Int. J. Dev. Biol.}

Mitochondria and lipid metabolism in mammalian oocytes and early embryos

Josephine Bradley and Karl Swann

Int. J. Dev. Biol. (2019) 63: 93-103

https://doi.org/10.1387/ijdb.180355ks

Dying to survive - apoptosis, necroptosis, autophagy as supreme experiments of nature

Mauro Piacentini and Guido Kroemer

Int. J. Dev. Biol. (2015) 59: 5-9

https://doi.org/10.1387/ijdb.150167mp

Transformation of the mitochondrial genome

Véronique Larosa and Claire Remacle

Int. J. Dev. Biol. (2013) 57: 659-665

https://doi.org/10.1387/ijdb.130230cr

Modulation of mitochondrial biogenesis and bioenergetic metabolism upon in vitro and in vivo differentiation of human ES and iPS cells

Alessandro Prigione and James Adjaye

Int. J. Dev. Biol. (2010) 54: 1729-1741

https://doi.org/10.1387/ijdb.103198ap

Sperm mitochondria diaphorase activity - a gene mapping study of recombinant inbred strains of mice

Aniela Golas, Paulina Malek, Malgorzata Piasecka and Jozefa Styrna

Int. J. Dev. Biol. (2010) 54: 667-673

https://doi.org/10.1387/ijdb.082778ag

Organelles in developing neurons: essential regulators of neuronal morphogenesis and function

Sayaka Sekine, Masayuki Miura and Takahiro Chihara

Int. J. Dev. Biol. (2009) 53: 19-27

https://doi.org/10.1387/ijdb.082618ss
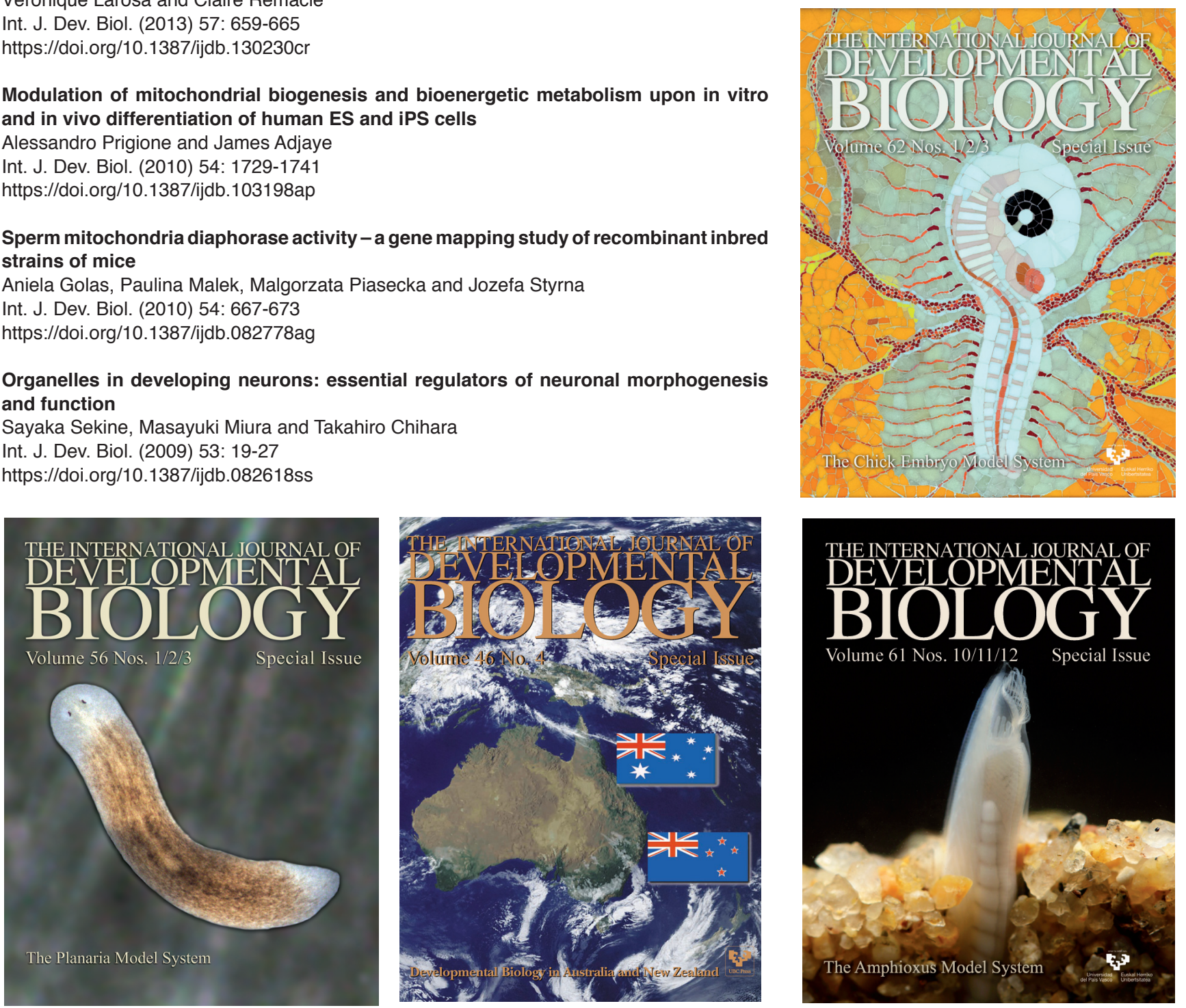